\title{
Power Electronics for PV-Based Communal Grids
}

\author{
Nicholas Opiyo \\ Energy Research Institute, SCAPE, University of Leeds, Leeds, UK \\ Email: elno@leeds.ac.uk
}

Received 9 January 2016; accepted 15 February 2016; published 18 February 2016

Copyright (C) 2016 by author and Scientific Research Publishing Inc.

This work is licensed under the Creative Commons Attribution International License (CC BY). http://creativecommons.org/licenses/by/4.0/

(c) (i) Open Access

\begin{abstract}
In this paper power electronics used in PV power generation systems have been reviewed and modelled. PV systems need converters for maximum power point tracking, power conditioning, voltage step-up/down as necessary, and for storage charge-controlling. Inverters are needed for AC loads and for utility grid interfacing. The four basic DC-DC converters commonly used with PV systems have been reviewed and modelled. Different DC-AC inverter types and operational architectures have also been reviewed with the two-stage DC-AC inverter, with the point of common coupling (PCC) at the inverter input, suggested as the most cost-effective and efficient architecture for PV-based communal grids. This is because only one inverter is used for the entire system as opposed to an inverter for every module string, resulting in higher efficiencies, low cost, and low harmonic distortions when compared to systems with PCC at AC terminal. The aim of power conversion/inversion is to extract maximum power possible from the PV system and where necessary, to invert it at close to $\mathbf{1 0 0 \%}$ as possible. Highlight: 1) DC-DC converters are necessary for power conditioning in PV systems; 2) DC-AC inverters are necessary for AC loads and for utility grid interfacing; 3) DC-AC inverters are also used to control the PV systems when grid connected; 4) Best inverter configuration cost-effectively and efficiently allows easy system modifications.
\end{abstract}

\section{Keywords}

Power Electronics, PV, Communal Grids, Modelling, Control Architecture

\section{Introduction}

A PV power system consists of PV power generators supplying DC or AC power to a system of loads through a system of power electronics as schematically shown in Figure 1. The system could either be in stand-alone configuration or in grid-connected configuration. In most cases, since PV power source (solar radiation) fluctuates with time and environmental conditions, back-up storage systems are usually used with the PV systems to en- 


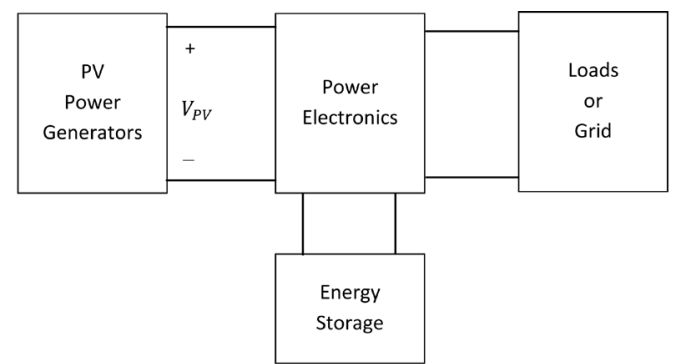

Figure 1. Schematic diagram of Islanded PV power generation system.

sure uninterrupted supply of power at all times. The power electronics comprise of DC-DC converters needed for power conditioning and maximum power point tracking (MPPT), DC-AC inverters in cases of AC loads or utility-grid interfacing, filter to remove harmonic distortions from the inverters, and charge controllers for the energy storage systems. The latter is usually implemented using bi-directional DC-DC Buck-Boost converters.

\subsection{DC-DC Converters}

The main functions of DC-DC converters are to operate the PV power generator at maximum power point under all conditions and to efficiently step up/down the voltage from the PV source to a stable DC voltage of desired magnitude. They are also used for controlling battery charging and discharging. The four basic DC-DC converters used with PV systems are Buck, Boost, Buck-Boost, and Cuk converters.

\subsubsection{DC-DC Buck (Step-Down) Converter}

A circuit diagram of a Buck converter with switching period $T$ and duty cycle $D$ is shown in Figure 2 . These converters are used to step-down voltage from the PV source to a lower voltage.

In continuous conduction mode, applying Kirchhoff's voltage law (KVL) to the loop containing the inductor and Kirchhoff's current law (KCL) on the node with the capacitor branch connected to it, we can model the dynamics of the inductor current $i_{L}(t)$ and the capacitor voltage $v_{C}(t)$ as follows [1]:

When switch $Q$ is on

$$
\left\{\begin{array}{l}
\frac{\mathrm{d} i_{L}}{\mathrm{~d} t}=\frac{1}{L}\left(V_{i n}-v_{o}\right) \\
\frac{\mathrm{d} v_{o}}{\mathrm{~d} t}=\frac{1}{C}\left(i_{L}-\frac{v_{o}}{R}\right), \quad 0<t<\mathrm{d} T, \quad Q: O N .
\end{array}\right.
$$

When switch $Q$ is off

$$
\left\{\begin{array}{l}
\frac{\mathrm{d} i_{L}}{\mathrm{~d} t}=\frac{1}{L}\left(-v_{o}\right) \\
\frac{\mathrm{d} v_{o}}{\mathrm{~d} t}=\frac{1}{C}\left(i_{L}-\frac{v_{o}}{R}\right), \quad \mathrm{d} T<t<T, \quad Q: O F F .
\end{array}\right.
$$

\subsubsection{DC-DC Boost (Step-Up) Converter}

Figure 3 shows a circuit diagram of a DC-DC Boost converter with switching period $T$ and duty cycle $D$.

In continuous conduction mode, we can use KVL and KCL to model the dynamics of the inductor current $i_{L}(t)$ and the capacitor voltage $v_{C}(t)$ as follows [1]:

When switch $Q$ is on

$$
\left\{\begin{array}{l}
\frac{\mathrm{d} i_{L}}{\mathrm{~d} t}=\frac{1}{L}\left(V_{i n}\right) \\
\frac{\mathrm{d} v_{o}}{\mathrm{~d} t}=\frac{1}{C}\left(-\frac{v_{o}}{R}\right), \quad 0<t<\mathrm{d} T, \quad Q: O N .
\end{array}\right.
$$


When switch $Q$ is off

$$
\left\{\begin{array}{l}
\frac{\mathrm{d} i_{L}}{\mathrm{~d} t}=\frac{1}{L}\left(V_{i n}-v_{o}\right) \\
\frac{\mathrm{d} v_{o}}{\mathrm{~d} t}=\frac{1}{C}\left(i_{L}-\frac{v_{o}}{R}\right), \quad \mathrm{d} T<t<T, \quad Q: O F F .
\end{array}\right.
$$

\subsubsection{DC-DC Buck-Boost Converter}

Figure 4 shows a circuit diagram of a DC-DC Buck-Boost converter with switching period $T$ and duty cycle $D$.

As with the Buck and Boost converters discussed above, in continuous conduction mode, we can use KVL and KCL to model the dynamics of the inductor current $i_{L}(t)$ and the capacitor voltage $v_{C}(t)$ as follows [1]:

When switch $Q$ is on

$$
\left\{\begin{array}{l}
\frac{\mathrm{d} i_{L}}{\mathrm{~d} t}=\frac{1}{L}\left(V_{i n}\right) \\
\frac{\mathrm{d} v_{o}}{\mathrm{~d} t}=\frac{1}{C}\left(-\frac{v_{o}}{R}\right), \quad 0<t<\mathrm{d} T, \quad Q: O N .
\end{array}\right.
$$

When switch $Q$ is off

$$
\left\{\begin{array}{l}
\frac{\mathrm{d} i_{L}}{\mathrm{~d} t}=\frac{1}{L}\left(v_{o}\right) \\
\frac{\mathrm{d} v_{o}}{\mathrm{~d} t}=\frac{1}{C}\left(-i_{L}-\frac{v_{o}}{R}\right), \quad \mathrm{d} T<t<T, \quad Q: O F F .
\end{array}\right.
$$

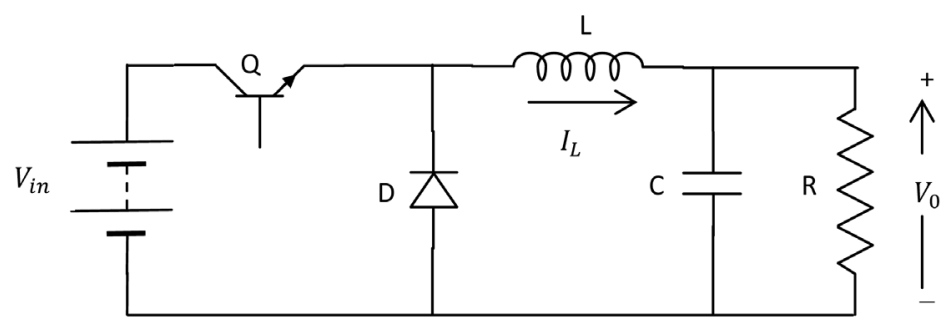

Figure 2. DC-DC Buck converter.

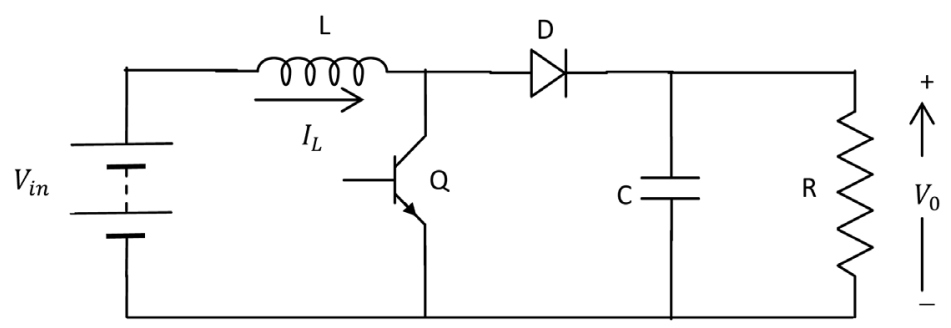

Figure 3. DC-DC Boost converter.

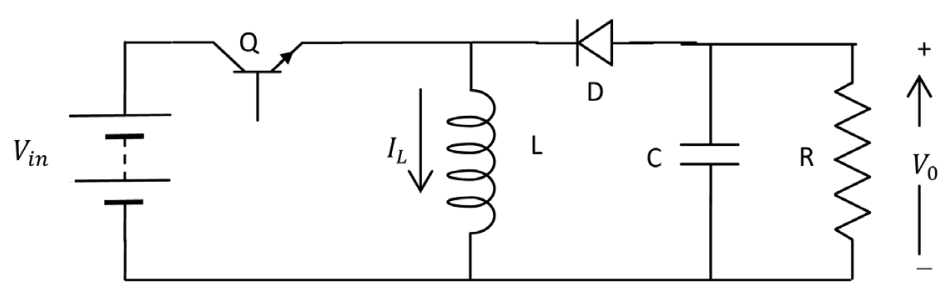

Figure 4. DC-DC Buck-Boost converter. 


\subsubsection{DC-DC Cuk Converter}

Figure 5 shows a circuit diagram of a DC-DC Cuk converter with switching period $T$ and duty cycle $D$.

In continuous conduction mode, we can use KVL and KCL to model the dynamics of the inductor current $i_{L}(t)$ and the capacitor voltage $v_{C}(t)$ as follows [1]:

When switch $Q$ is on

$$
\left\{\begin{array}{l}
\frac{\mathrm{d} i_{L 1}}{\mathrm{~d} t}=\frac{1}{L_{1}}\left(v_{i n}\right) \\
\frac{\mathrm{d} v_{c}}{\mathrm{~d} t}=\frac{1}{C_{2}}\left(-i_{L 2}\right) \\
\frac{\mathrm{d} i_{L 2}}{\mathrm{~d} t}=\frac{1}{L_{2}}\left(-v_{o}+v_{c}\right) \\
\frac{\mathrm{d} v_{o}}{\mathrm{~d} t}=\frac{1}{C_{1}}\left(i_{L 2}-\frac{v_{o}}{R}\right)
\end{array}\right.
$$

When switch $Q$ is off

$$
\left\{\begin{array}{l}
\frac{\mathrm{d} i_{L 1}}{\mathrm{~d} t}=\frac{1}{L_{1}}\left(v_{i n}-v_{o}\right) \\
\frac{\mathrm{d} v_{c}}{\mathrm{~d} t}=\frac{1}{C_{2}}\left(i_{L 1}\right) \\
\frac{\mathrm{d} i_{L 2}}{\mathrm{~d} t}=\frac{1}{L_{2}}\left(-v_{o}\right) \\
\frac{\mathrm{d} v_{o}}{\mathrm{~d} t}=\frac{1}{C_{1}}\left(i_{L 2}-\frac{v_{o}}{R}\right)
\end{array}, \quad \mathrm{d} T<t<T, \quad Q: O F F .\right.
$$

\subsection{DC-AC Inverters}

DC-AC Inverters are used in PV systems to convert DC generated voltage into AC voltage for AC loads or for utility grid interfacing and to control the active and reactive power [2]-[5]. A maximum power point tracker (MPPT), implemented using a DC-DC converter, is usually used with DC-AC inverters to ensure extraction of maximum power from the PV system. Filters with active damping are used to reduce harmonics from the inverters. Usually voltage source inverters (VSI) are used when interfacing PV systems with a utility grid. These usually have Buck characteristics, i.e., output voltage is usually lower than input voltage. However, step-up transformers can be used to boost the voltage. Capacitors are used to form DC links between DC-AC inverters and DC-DC converters to decouple power fluctuations in AC and DC sides. Inverters with transformers are also used to provide galvanic isolation between PV generators and the utility grid. The two types of inverters are transformerless and transformer-based inverters.

\subsubsection{Transformerless Inverters}

These systems use high frequency DC-DC converters for MPPT. Switching is done us the full bridge inverter.

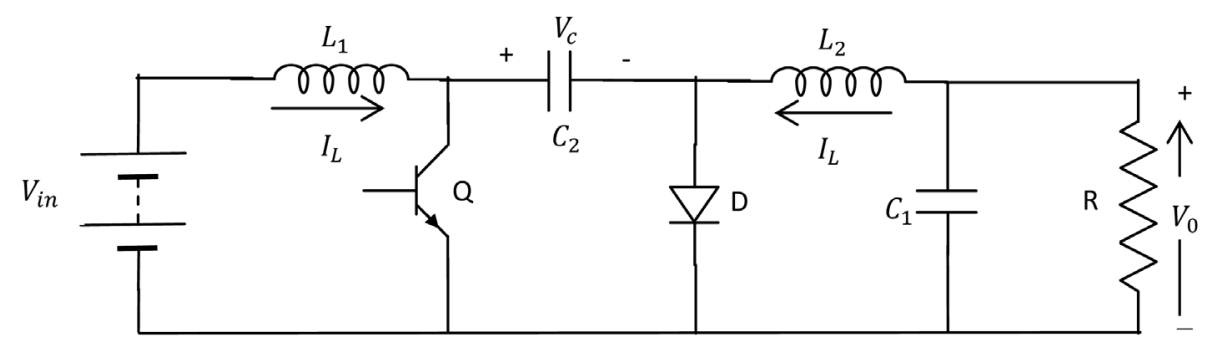

Figure 5. DC-DC Cuk converter. 
Neutral conductor of AC side connected to the inverter is grounded. Avoiding the use of transformers increases inverter efficiencies by $1 \%-3 \%$ [6]-[8]. Also, the cost, size, weight and complexity of the inverter are reduced. Moreover, topologies without transformers increase the control over the system voltage and power because transformers limit the control of the grid current. Avoiding transformers however result in galvanic connection of the grid and PV array; some countries like UK and Italy require inverters with transformers. Figure 6 shows a topology of a transformerless inverter.

\subsubsection{Transformer-Based Inverters}

These inverters use transformers to provide galvanic isolation of the PV system from the utility grid. The transformers also step up the voltages from the PV systems to grid levels. However, use of transformers increases system costs and also lowers the efficiencies of the inverters. Moreover, the transformers increase the weight of the inverters. Transformer-based inverters use either high frequency transformers or line frequency transformers. A high frequency transformer based topology is shown in Figure 7. In order to reduce the switching losses on the high voltage side, the push-pull converter boosts the voltage to grid level and shapes the current waveform as well. A full bridge switched at line frequency is used in a second converter as an inverting stage. The two converters in series used in this topology reduce efficiency and make the control more complex.

A line frequency transformer-based topology with self-commutated full bridge is shown in Figure 8.

Inverters can further be classified as single-phase or three-phase. For residential applications, single-phase inverters are the most widely used as they are rated for up to $5 \mathrm{~kW}$. For large power interfacing, three-phase inverters are used. Depending on system configuration, inverters can be categorized as central inverters, string inverters, multi-string inverters, and AC module inverters.

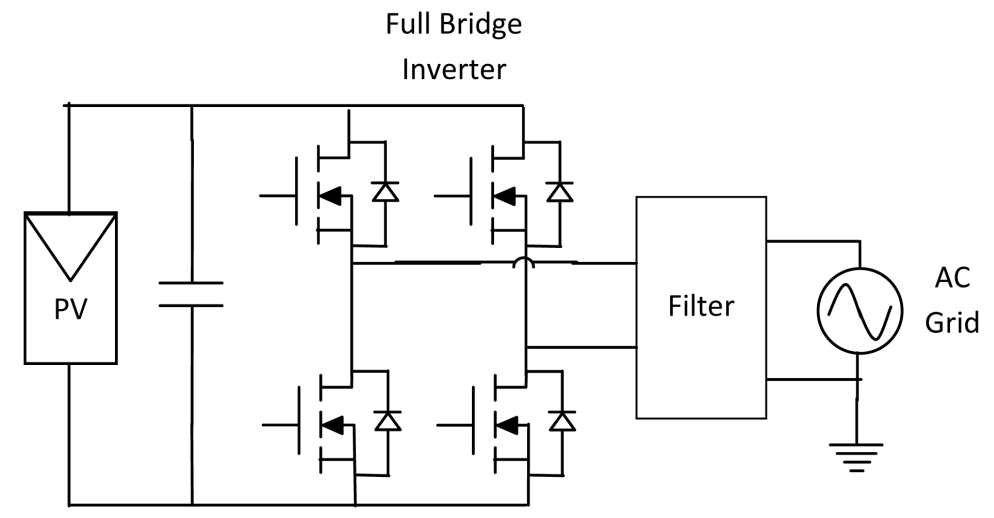

Figure 6. A transformerless inverter.

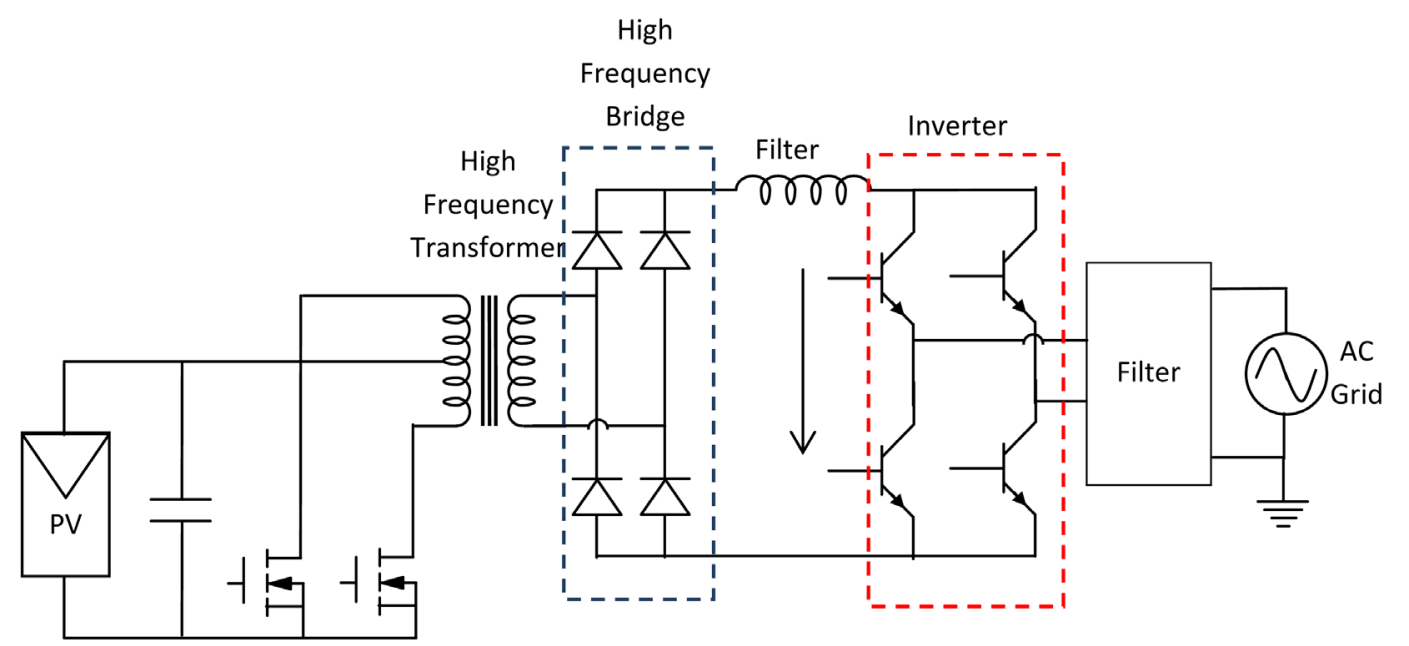

Figure 7. A high frequency transformer-based inverter. 


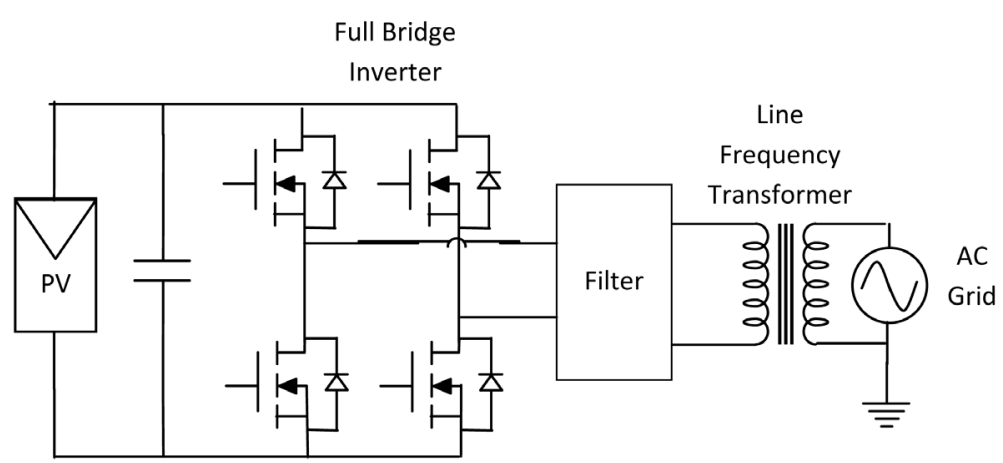

Figure 8. A line frequency transformer-based inverter.

\subsubsection{Central Inverters}

In these configurations, a PV array consisting of strings of PV modules connected in parallel, with each string comprising many modules connected in series, are connected to a single inverter as shown in Figure 9. The series and parallel connections of many modules ensure enough power output and thus eliminate the need for DC-DC Boost converters. They are available in several kW to $1 \mathrm{MW}$ range of power and can thus be used for almost all levels of voltage applications. Use of a single inverter reduces cost while enhancing efficiency. Moreover harmonics distortions associated with power electronics are also reduced. They are therefore the most widely used in medium to large scale PV systems [9]. The configuration has many drawbacks including diminished capability of MPPT due to shading and panel mismatch and degradation, losses due to string diodes used to connect module-strings in parallel, and non-flexibility of the design [10].

\subsubsection{String Inverters}

These are reduced power versions of the centralized inverter configuration. They have separate MPPT for each PV module string as shown in Figure 10. They offer more efficient harnessing of generated power and reduced losses due to string diodes [9]. This type of configuration also allows use of many module strings of different capacities and orientations. They are available in the $0.4 \mathrm{~kW}$ to $2 \mathrm{~kW}$ power ranges and are thus mainly used in low power applications with single-phase full-bridge topologies with low frequency transformers on the AC side for isolation [9]. These configurations also do not allow design flexibility which is important due to modular nature of PV systems. They are also more expensive than centralized systems due to their low power units and use of multiple inverters.

\subsubsection{Multi-String (Two-Stage) Inverters}

Connecting a DC-DC converter with MPPT capabilities between each module string and a DC-AC inverter greatly increases a system's performance and modularity [11]. In Figure 11, the point of common coupling (PCC) is at the ac terminal. The output from the DC-DC converter can either be a low ripple DC voltage or a modulated current that follows a rectified sine wave. If the output is a low ripple DC voltage, the DC/DC converter handles MPPT and voltage boost if necessary. The DC-AC inverter then acts as a voltage sourced inverter (VSI) that handles the output current regulation and DC bust voltage regulation. The VSI usually uses a self-communicating half/full-bridge rectifier as its switching circuit [12]. If the output is a modulated current, the DC-DC converter handles MPPT and output current regulation while DC-AC inverter switches at the grid frequency to unfold the rectified sine wave [12]. Many converters/inverters used in these systems increase cost, reduce system efficiency, increase power losses, and increase harmonic distortions. These configurations have power ranges of $1 \mathrm{~kW}$ to $6 \mathrm{~kW}$ and are thus suitable for residential applications [9].

In Figure 12, multiple DC-DC converters feed a single VSI. The DC-DC converters handle MPPT and voltage boost if necessary while the central DC-AC inverter is a VSI which handles the output current regulation and intermediate DC bus voltage regulation [12]. This system is the best configuration for small communal grids as only one inverter is used for the entire system as opposed to an inverter for every module string. This results in higher efficiencies, low cost, and low harmonic distortions when compared to systems with PCC at AC terminal. 


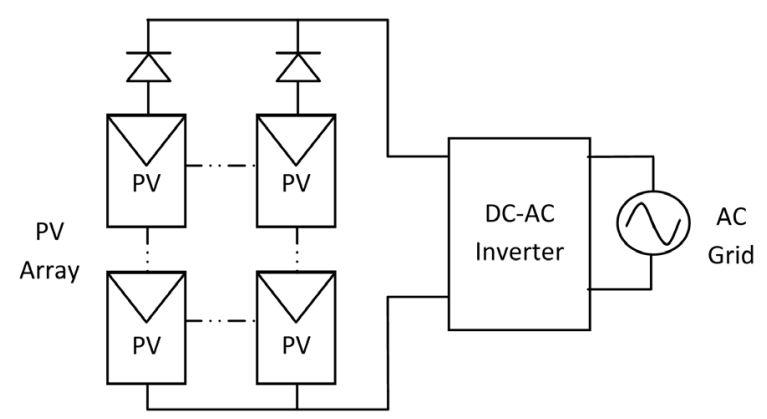

Figure 9. Central Inverter.

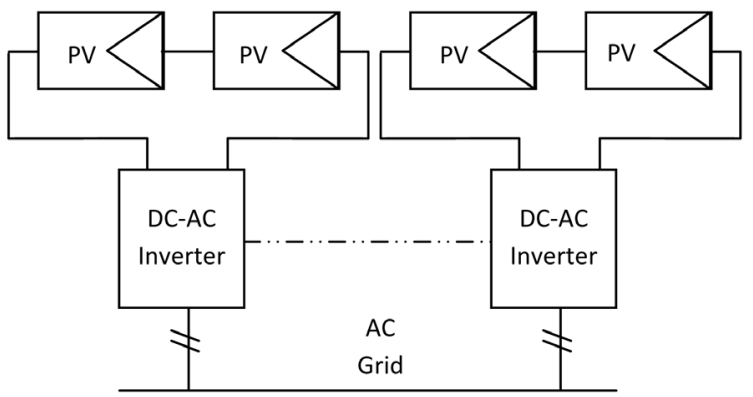

Figure 10. Reduced power version of single stage centralized DC-AC inverter.

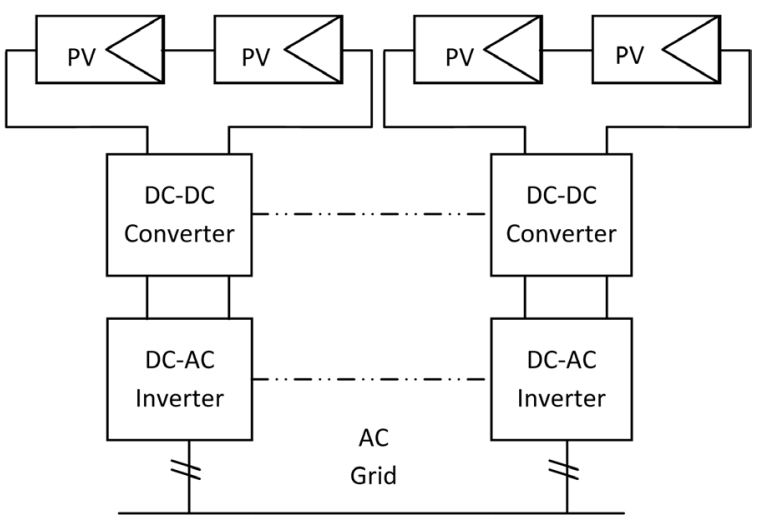

Figure 11. Two stage multi-string inverter with PCC at AC terminal.

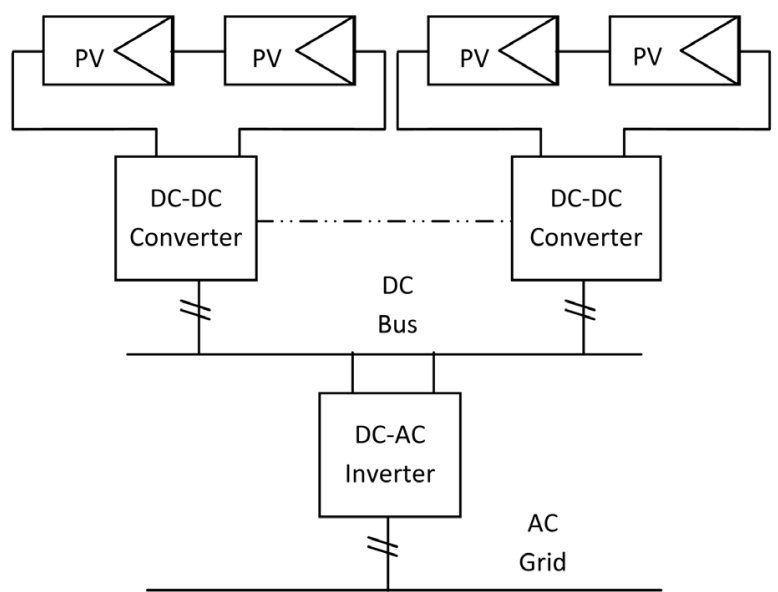

Figure 12. Two stage DC-AC inverter with PCC at DC-AC inverter input. 


\subsubsection{AC Module Inverters}

In this arrangement, each module has its own inverter and MPPT control. Several module inverters are used to compensate the high power level as this inverter configuration has lower power handling capability. This configuration has several disadvantages in addition to low power handling capability, including low efficiency due to use of too many inverters, high cost, low lifetime, and high harmonic distortions [13]. Figure 13 shows an AC module inverter configuration.

Factors to consider when deciding on inverters:

Efficiency: Any reduction in an inverter efficiency immediately reflects on a PV systems overall efficiency. European efficiency of PV inverters is an accepted standard for comparing efficiencies of different inverters and it is expressed as [3]

$$
\eta_{\text {EURO }}=0.03 \eta_{5 \%}+0.06 \eta_{10 \%}+0.13 \eta_{20 \%}+0.1 \eta_{30 \%}+0.48 \eta_{50 \%}+0.2 \eta_{100 \%}
$$

where $0.03 \eta_{5 \%}$ means the inverter is operating at $5 \%$ efficiency for a period of 0.03 time period out of the total operating time, $0.06 \eta_{10 \%}$ means the inverter is operating at $10 \%$ efficiency for a period of 0.06 time period out of the total operating time, and so on. This system therefore considers the fractions of time that an inverter will operate at partial loads or different levels of irradiation.

- Anti-Islanding Protection: Inverters should automatically disconnect from the utility grid in case of a fault with the latter. This protects systems upstream from frequency and phase related damages due to power injection from the inverter.

- Harmonic Distortions: Harmonics from inverters should be minimized to reduce distortions in the utility grid voltage and current. This can be achieved by connecting low-pass filters between the inverters and the grid.

- The inverter should be able to adjust with the dynamics of MPPT operation using changing environmental (irradiance) conditions for maximum power harnessing from the PV system.

- Modifiability and Cost: Inverter configurations should take into account the modular nature of PV systems to minimize associated costs.

\section{Simulations and Results}

\subsection{DC-DC Buck Converter}

Equations (1) and (2) are implemented in Simulink as shown in Figure 14 and subsequently fed into 2 integrators to obtain the $i_{L}(t)$ and $v_{C}(t)$ states [14]-[16]. To avoid use of complex equations, the electrical and semiconductor devices are represented as ideal components (zero ON voltages, zero OFF currents, zero switching times). Auxiliary binary variables can therefore be used to determine the states of the switches. The equations obtained by the use of Kirchhoff's laws should include all permissible states due to power semiconductor devices being ON or OFF.

A pulse width modulation (PWM) signal is used to control the switch $\mathrm{Q}$ to help with subsequent simulation analyses and feedback controller verification. Trigger pulses derived using a repeating sequence generator and duty cycle block are used by the converter to verify that it is working in open loop configuration; a function block compares the duty cycle while saw tooth from the trigger pulses are connected as an input to the switch control. Inputs for the masked subsystem are therefore duty ratio and input voltage, while the outputs are chosen
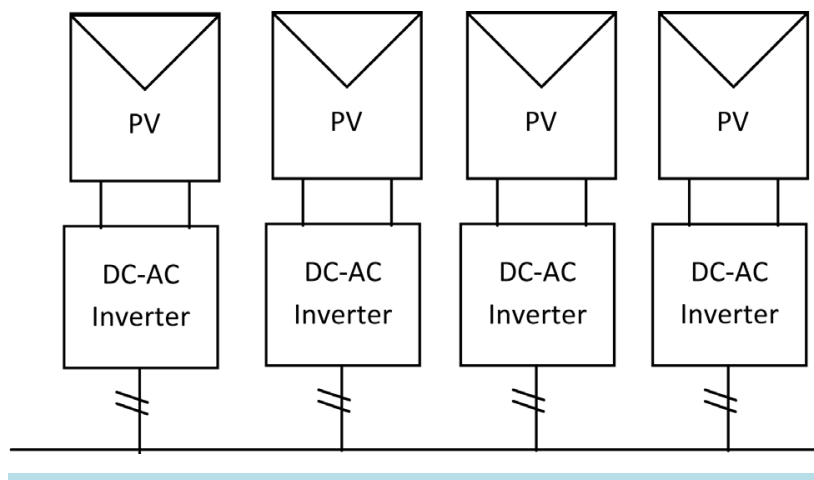

AC

Grid

Figure 13. AC module inverter. 


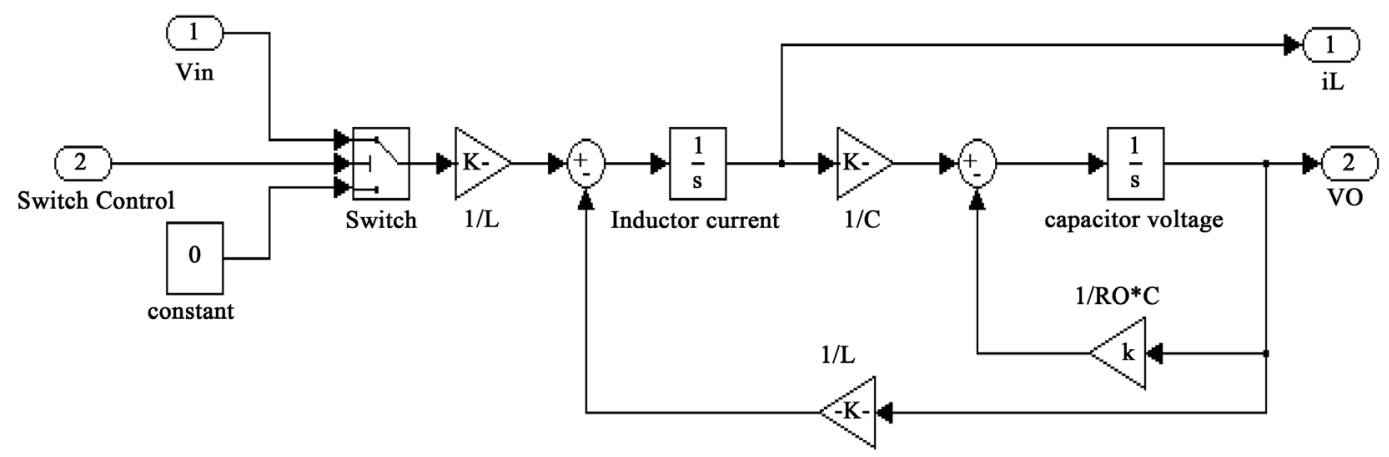

Figure 14. Simulink model of an Open-Loop DC-DC Buck converter.

to be inductor current, capacitor voltage, and output voltage [16]. Figure 15 shows the inductor current and capacitor voltage simulation results for an open-loop DC-DC Buck converter.

\subsection{DC-DC Boost Converter}

Equations (3) and (4) are implemented in Simulink as shown in Figure 16 and subsequently fed into 2 integrators to obtain the $i_{L}(t)$ and $v_{C}(t)$ states [14]-[16].

Figure 17 shows the inductor current and capacitor voltage for open loop simulation for an open-loop DC-DC Boost converter implemented using a PWM.

\subsection{DC-DC Buck-Boost Converter}

Equations (5) and (6) are implemented in Simulink as shown in Figure 18 and subsequently fed into 2 integrators to obtain the $i_{L}(t)$ and $v_{C}(t)$ states [14]-[16].

Figure 19 shows the inductor current and capacitor voltage for open loop simulation for an open-loop DC-DC Buck-Boost converter implemented using a PWM.

\subsection{DC-DC Cuk Converter}

Equations (7) and (8) are implemented in Simulink as shown in Figure 20 and subsequently fed into 2 integrators to obtain the $i_{L}(t)$ and $v_{C}(t)$ states [14]-[16].

Figure 21 shows the inductor current and capacitor voltage for open loop simulation for an open-loop DC-DC Cuk converter implemented using a PWM.

\subsection{Grid Connected PV Power System}

Figure 22 shows power electronics in a grid connected PV system without back-up battery. The function of the DC-DC Boost converter is to operate the array at maximum power point under all conditions and to efficiently step up $V_{P V}$ to a higher DC voltage $V_{D C}$. The DC-AC inverter generates an AC output current $i_{a c}$ in phase with the AC utility grid voltage $v_{a c}$ and also balances the average power delivery from the PV array to the grid,

$$
P_{a c}=P_{P V} \times \eta_{D C-D C} \times \eta_{D C-A C}
$$

The aim is to achieve a power-conversion-efficiency close to $100 \%$, i.e.

$$
\eta_{\text {converter }}=\frac{P_{a c}}{P_{P V}}=\frac{V_{R M S} I_{R M S}}{V_{P V} I_{P V}}
$$

The purpose of the capacitor is to provide energy storage to balance the difference between $P_{P V}$ and instantaneous power $p_{a c}(t)$. The system is disconnected from the grid when utility loses power.

The control variable for the DC-AC inverter is the RMS current reference $I_{R M S r e f}$. The DC/AC inverter current $i_{a c}(t)$ is controlled so that it is in phase with the grid voltage $v_{a c}(t)$ and so that it's RMS value equals the reference; $I_{R M S}=I_{R M S r e f}$. 

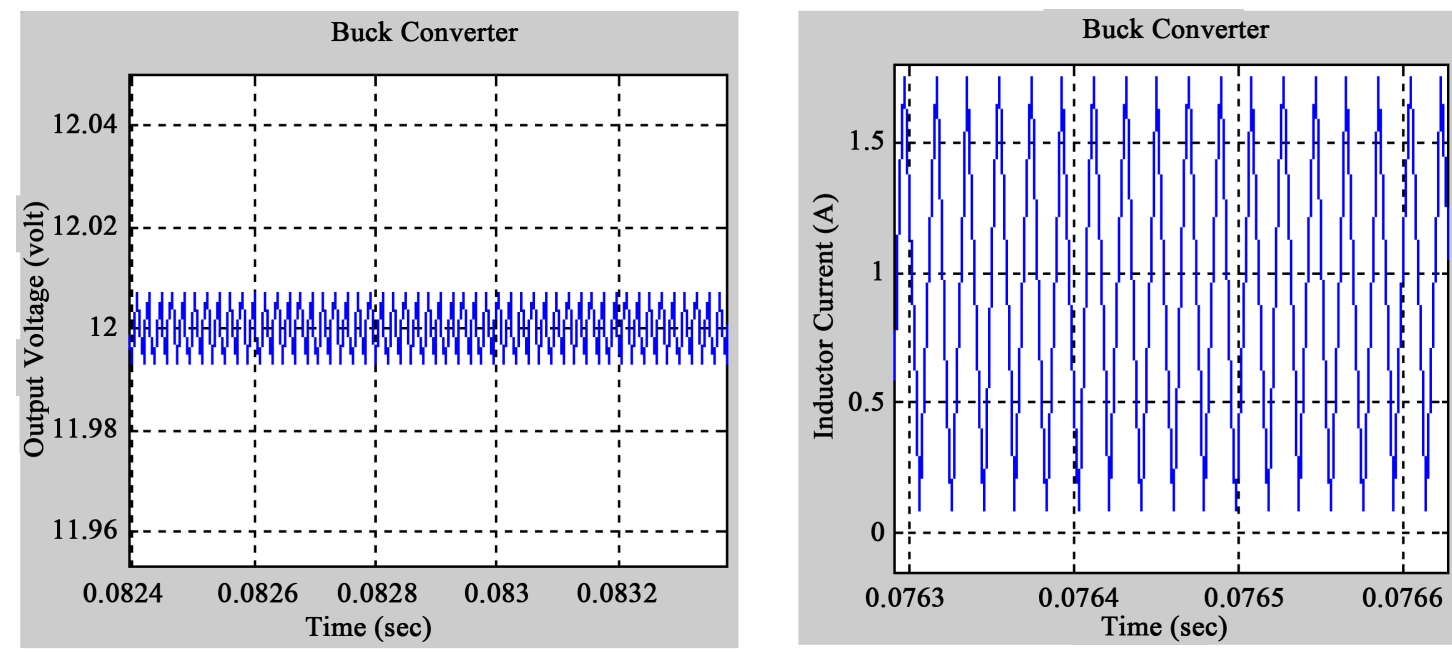

Ripple (peak-to-peak $=0.11 \%$ )

Figure 15. Capacitor voltage and inductor current for an open-loop DC-DC Buck converter.

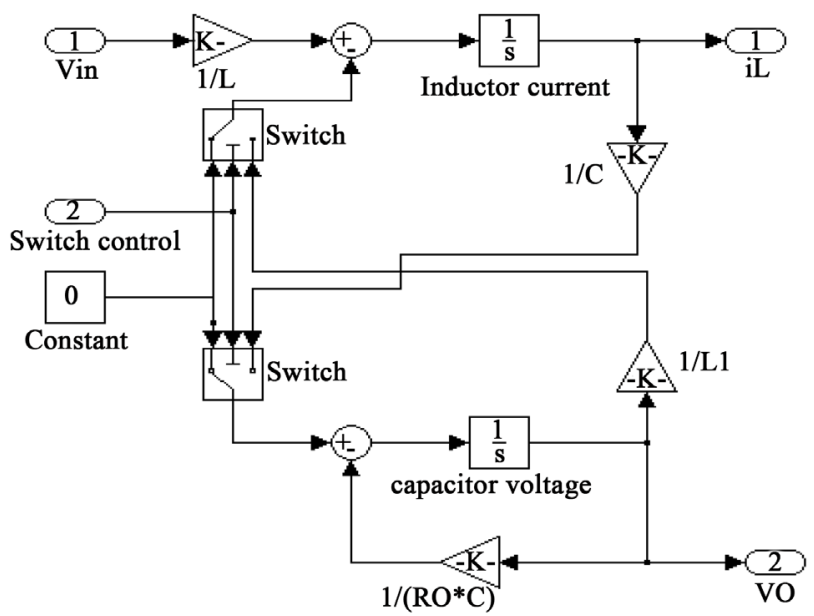

Figure 16. Simulink model of an open-loop DC-DC Boost converter.
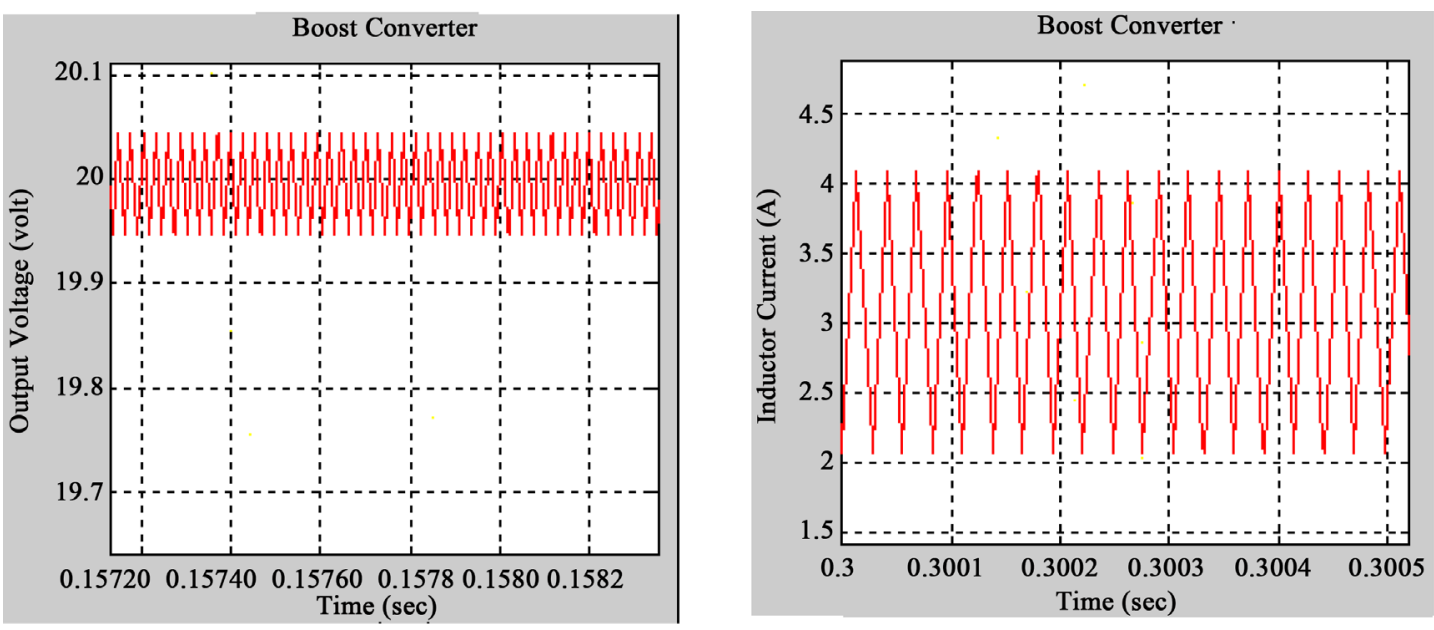

Ripple (peak-to-peak $=0.43 \%)$

Figure 17. Capacitor voltage and inductor current for an open-loop DC-DC Boost converter. 


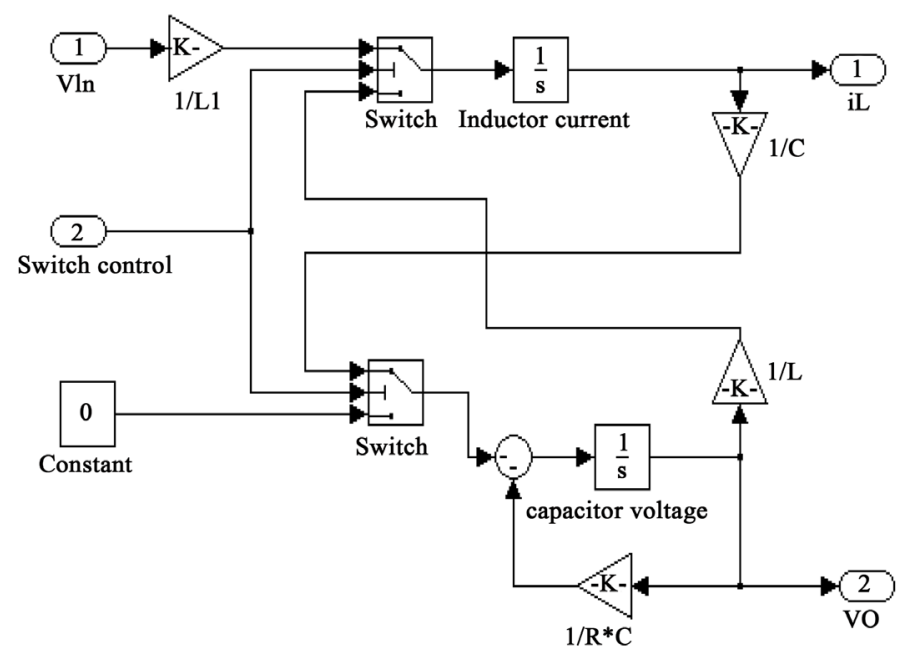

Figure 18. Simulink model of an open-loop DC-DC Buck-Boost converter.
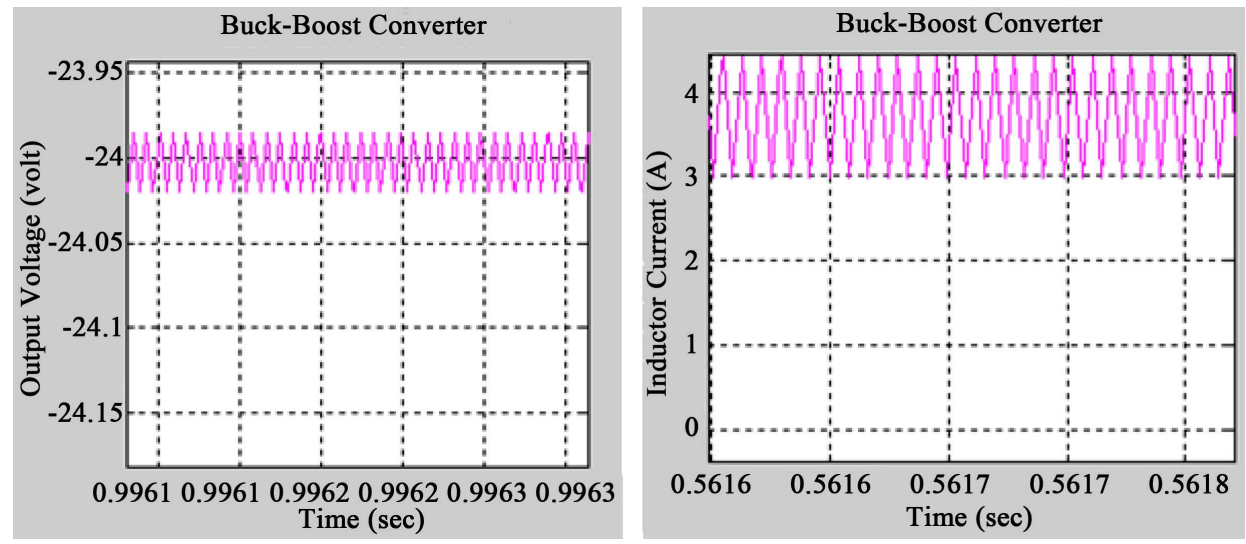

Ripple (peak-to-peak $=0.12 \%)$

Figure 19. Capacitor voltage and inductor current for an Open-Loop DC-DC Buck-Boost converter.

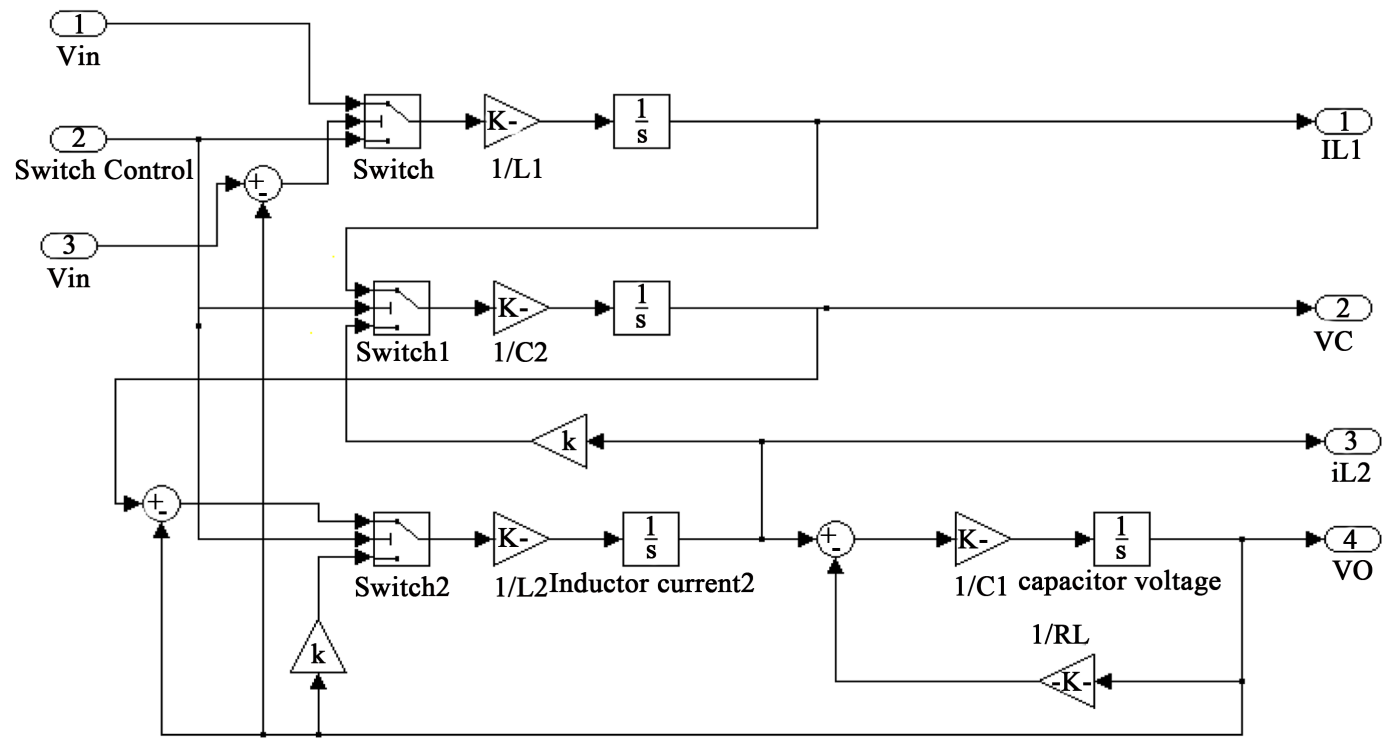

Figure 20. Simulink model of an open-loop DC-DC Cuk converter. 

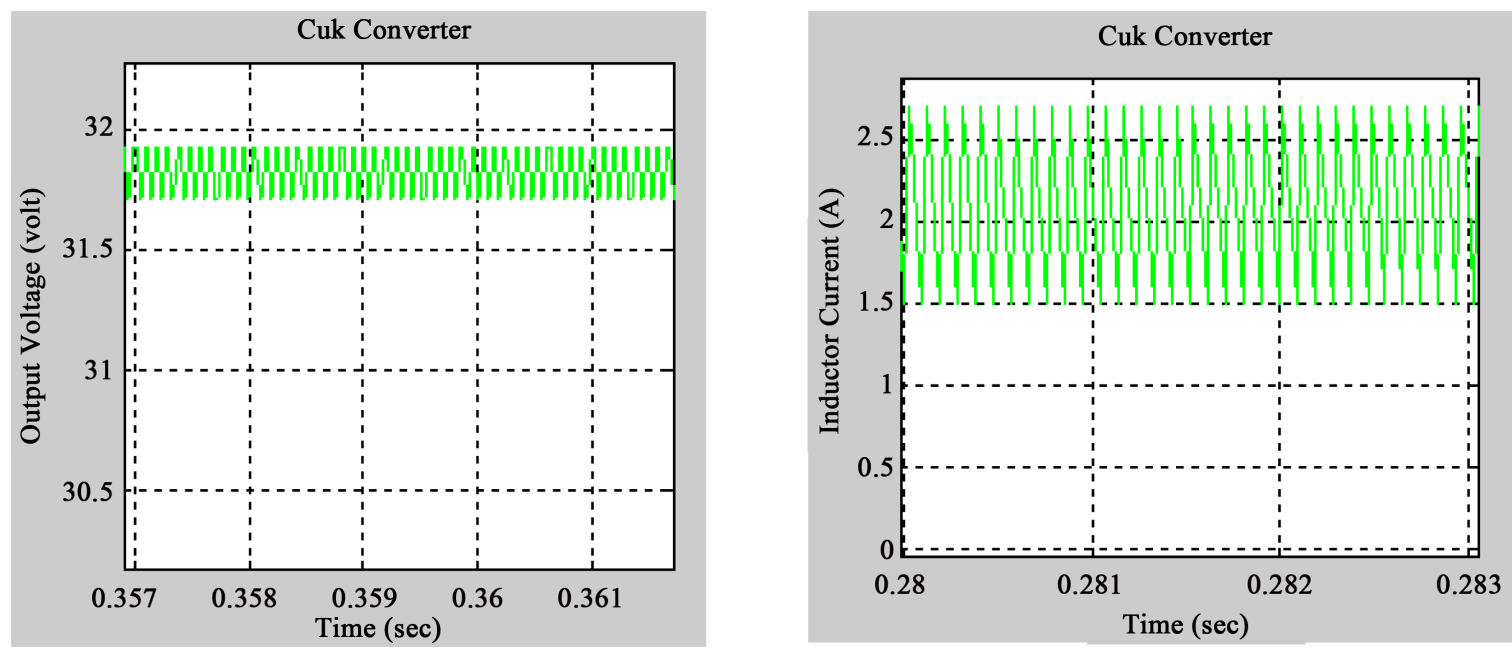

Ripple (peak-to-peak $=1.96 \%)$

Figure 21. Capacitor voltage and inductor current for an open-loop DC-DC Cuk converter.

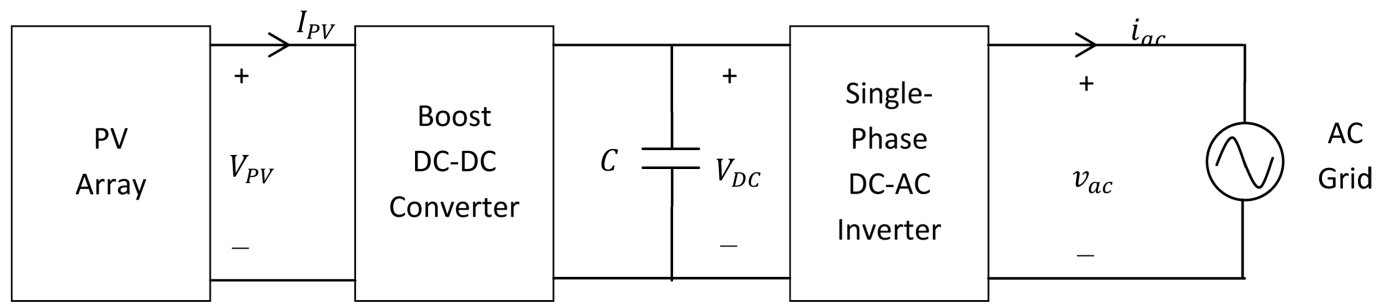

Figure 22. Power electronics in a grid-connected PV system.

Figure 23 shows a Simulink model of a grid-connected 6 module PV array with a DC-DC Boost converter and a DC-AC inverter used to implement (Figure 22). Each module is rated $85 \mathrm{Wp}$ and therefore if the PV array operates at ideal conditions, total power generated $\left(P_{P V}\right)$ should be $510 \mathrm{Wp}$.

The AC grid RMS is set at $120 \mathrm{~V}$ while AC line frequency is set at $60 \mathrm{~Hz}$. In this simulation, the PV array voltage output $V_{P V}=103.2 \mathrm{~V}$, current output $I_{P V}=4.95 \mathrm{~A}$, and power output $P_{P V}=510.8 \mathrm{~W}$. These three values are fed into the DC-DC Boost converter which then outputs a $V_{D C}$ of $199.8 \mathrm{~V}$, representing a 96.6\% boost in $V_{P V}$. The boost power out $P_{P V}=492.6 \mathrm{~W}$, meaning the DC-DC converter has $96.43 \%$ efficiency. If we run the simulation using different values of $I_{R M S r e f}$ and observe the output voltage $V_{\text {out }}(t)=V_{D C}(t)$, we can determine the right $I_{R M S r e f}$ when $P_{a c} \approx P_{P V}$ and thus nearly 100\% conversion efficiency; in this case the ideal $I_{R M S r e f}$ was determined to be $3.94 \mathrm{~A}$, as shown in Figure 24 .

The $V_{D C}$ from the Boost converter is input into the DC-AC inverter where it is inverted into $V_{A C}$ for grid interface. Figure 25 shows a comparison of $V_{D C}$ and $V_{A C}$. While $V_{D C}$ ripples around $200 \mathrm{~V}$ with a mean of 199.5 V, $V_{A C}$ is a sine wave with amplitude of $169.7 \mathrm{~V}$ and a mean of $0 \mathrm{~V}$, and a frequency and period that matches that of the grid it is interfaces with.

Similarly, Figure 26 shows a comparison of $I_{P V}$ and $I_{A C}$ from the DC-AC inverter. $I_{P V}$ ripples between $0 \mathrm{~A}$ and $4.95 \mathrm{~A}$, while $I_{A C}$ is a sine wave with an amplitude of $5.57 \mathrm{~A}$ and a mean of $0 \mathrm{~A}$, and a frequency and period that matches that of the grid it is interfaces with.

As shown in Figure 27, the averaged input AC power is $493.2 \mathrm{~W}$ while the averaged output AC power is $472.8 \mathrm{~W}$, therefore the DC-AC inverter efficiency is $95.86 \%$. From Equation (12), the overall conversion efficiency is given by

$$
\eta_{\text {converter }}=\frac{P_{a c}}{P_{P V}}=\frac{472.8}{510.8} \times 100=92.56 \%
$$

Average power balance can be implemented through an automatic feedback control as shown in Figure 28. 


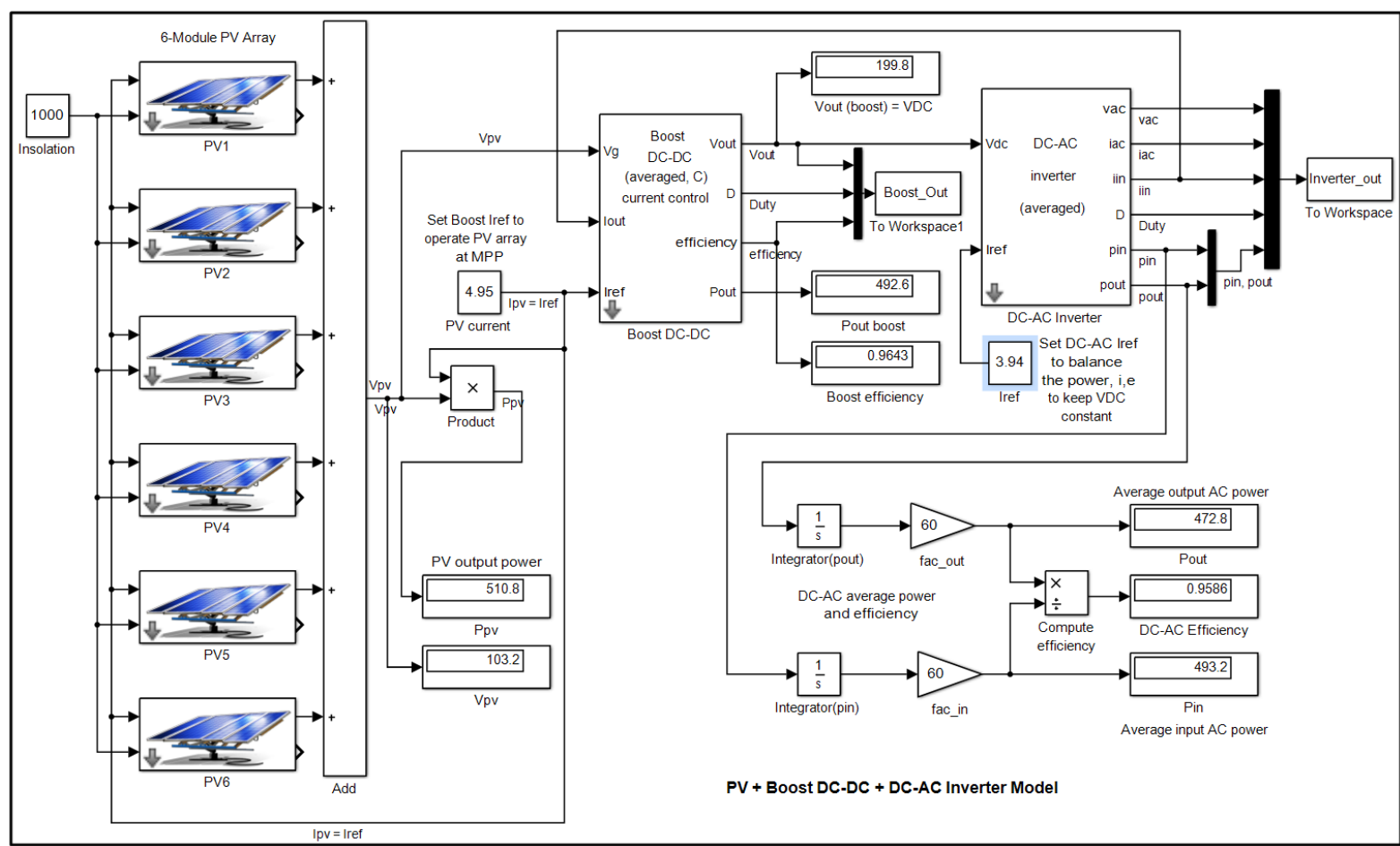

Figure 23. Simulink model of a grid-connected PV system with DC-DC and DC-AC converters.

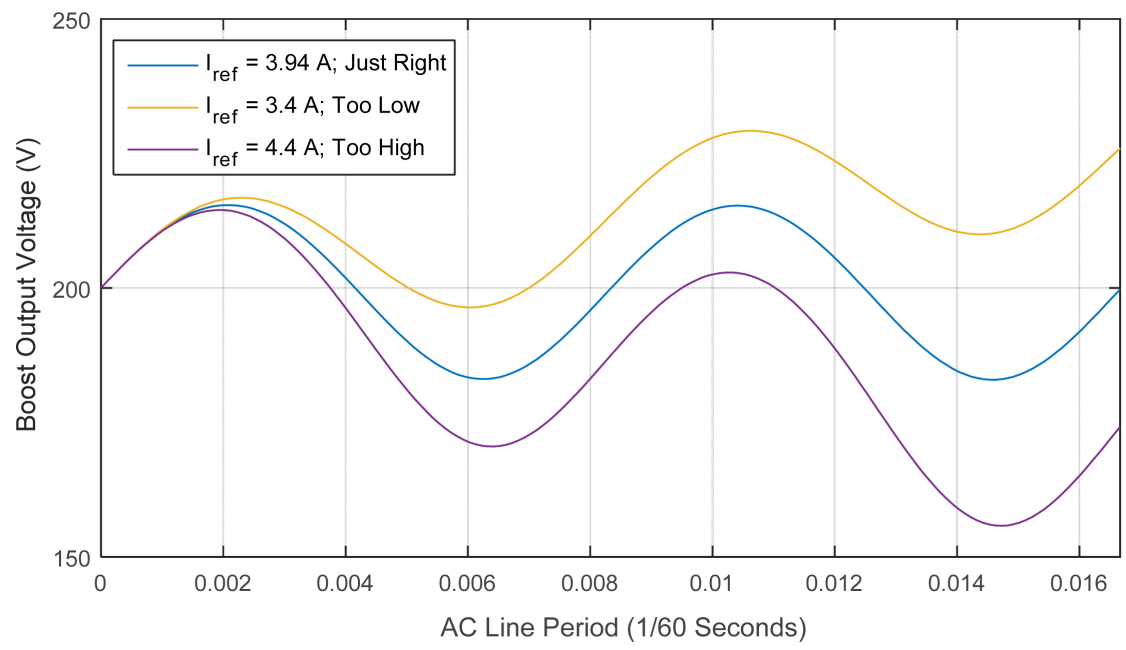

Figure 24. Simulation results for different $I_{\text {RMSref }}$ values.

The voltage $V_{D C}$ is sensed and compared to a reference value $V_{D C r e f}$ and the difference is the error signal of the feedback controller. If the error is positive $\left(V_{D C}>V_{D C r e f}\right)$, the compensator increases $I_{R M S r e f}$. If the error is negative ( $\left.V_{D C}<V_{D C r e f}\right)$, the compensator decreases $I_{R M S r e f}$. In steady state $\left(V_{D C}=V_{D C r e f}\right)$, the error signal is zero as $I_{R M S r e f}$ is automatically adjusted by the automatic feedback controller so that it is just right and the average power delivered to the ac grid, $P_{a c}$ matches the power generated by the PV array, $P_{P V}$.

Figure 29 shows an analysis of storage capacitor C. As mentioned earlier, capacitor C provides energy storage necessary to balance instantaneous power delivered to the grid.

$$
P_{a c}-p_{a c}(t)=P_{a c}-p_{a c}(1-\cos 2 \omega t)=P_{a c} \cos 2 \omega t
$$




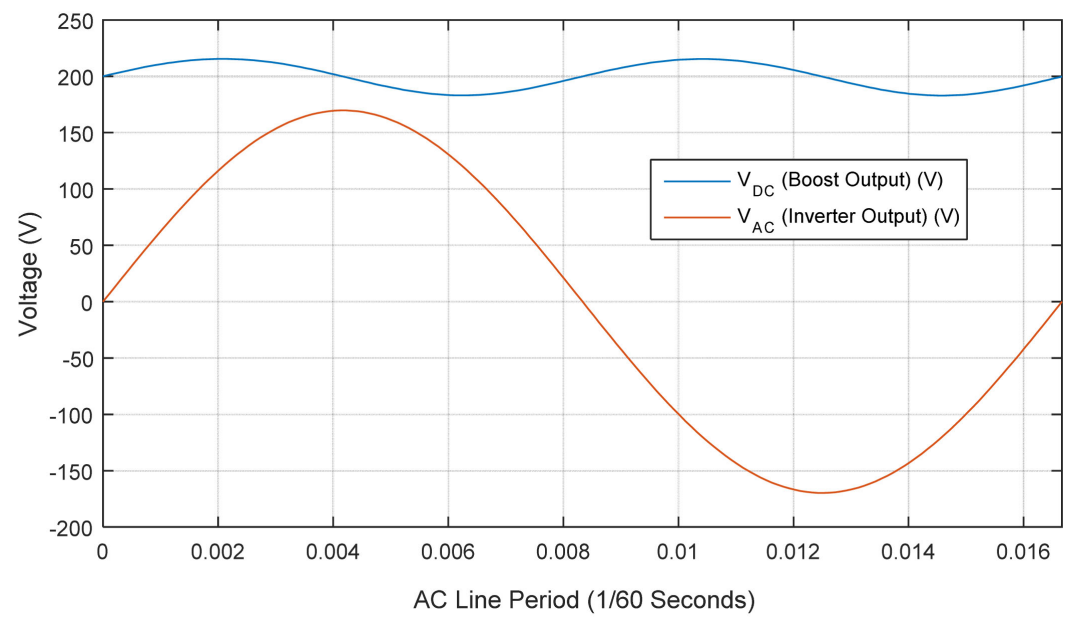

Figure 25. Comparison of $V_{D C}$ and $V_{A C}$ simulation results.

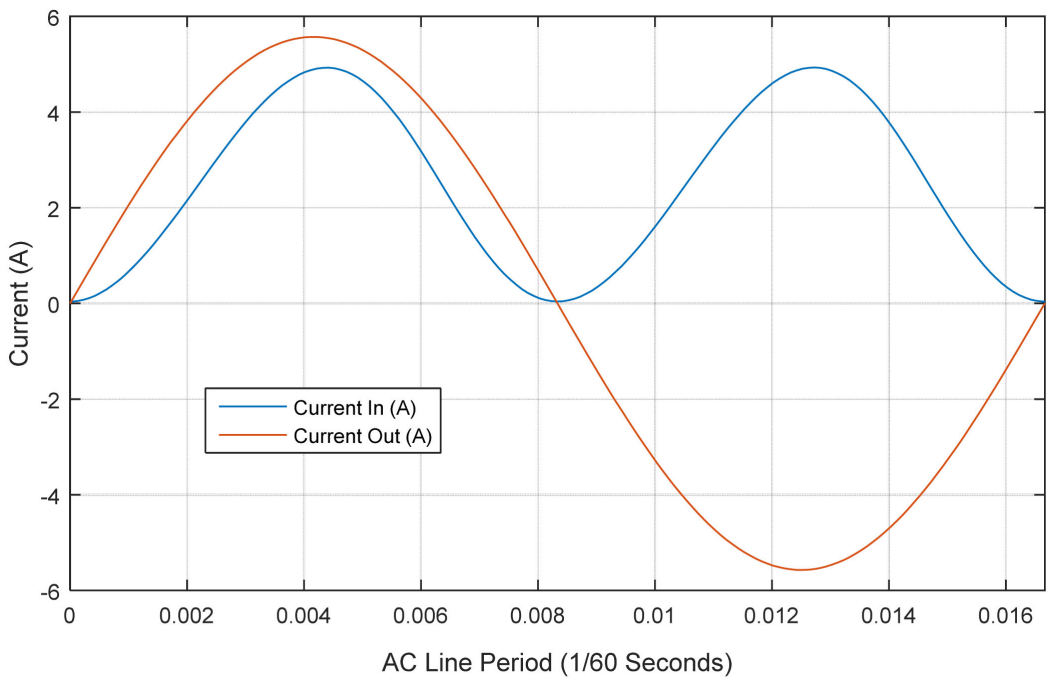

Figure 26. Comparison of $I_{P V}$ and $I_{A C}$ simulation results.

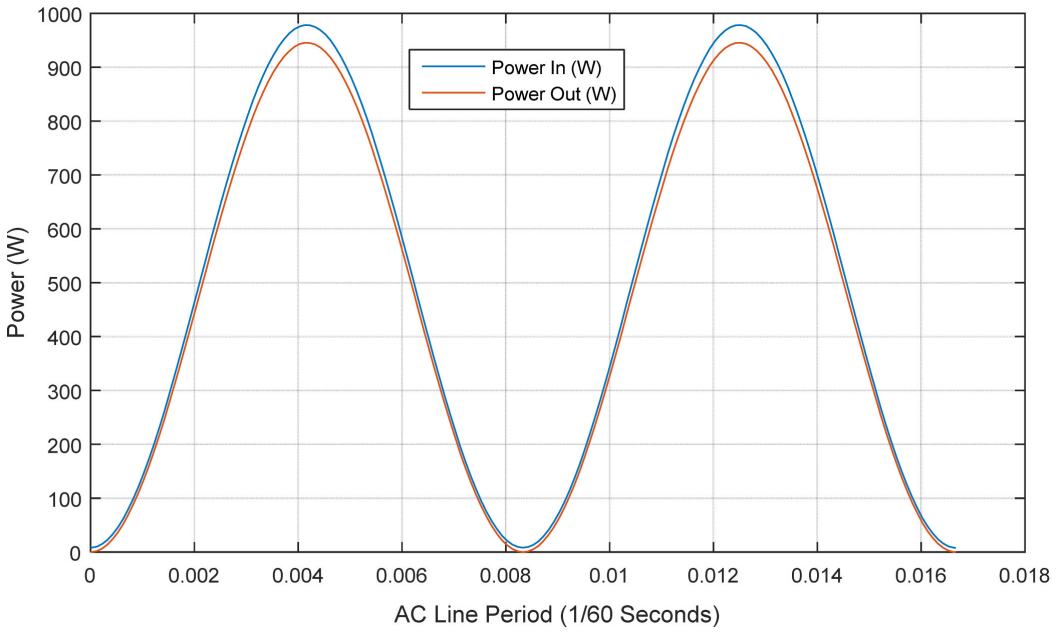

Figure 27. Comparison of $P_{P V}$ and $P_{A C}$ simulation results. 


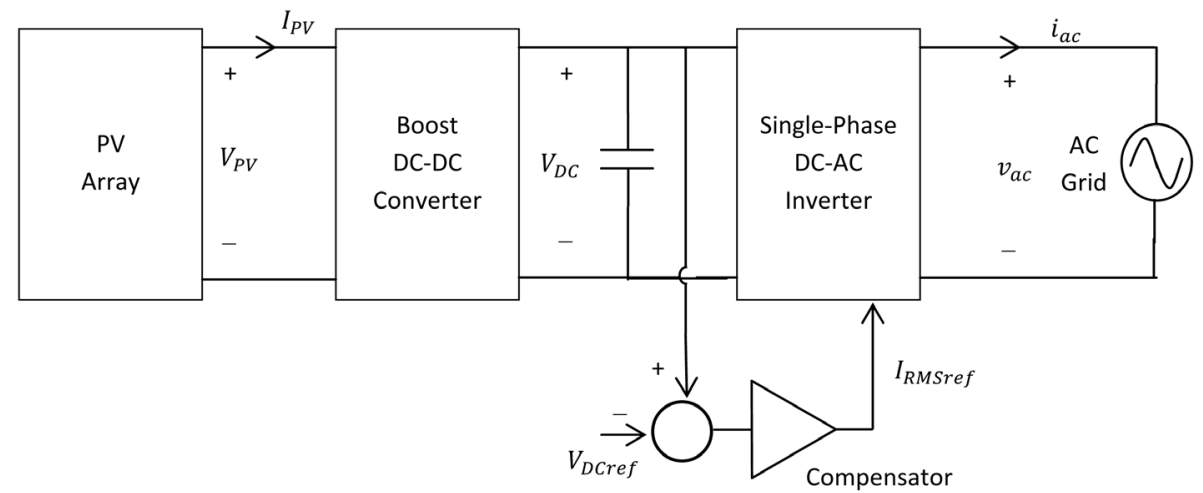

Figure 28. A grid-connected PV system with an automatic feedback loop.

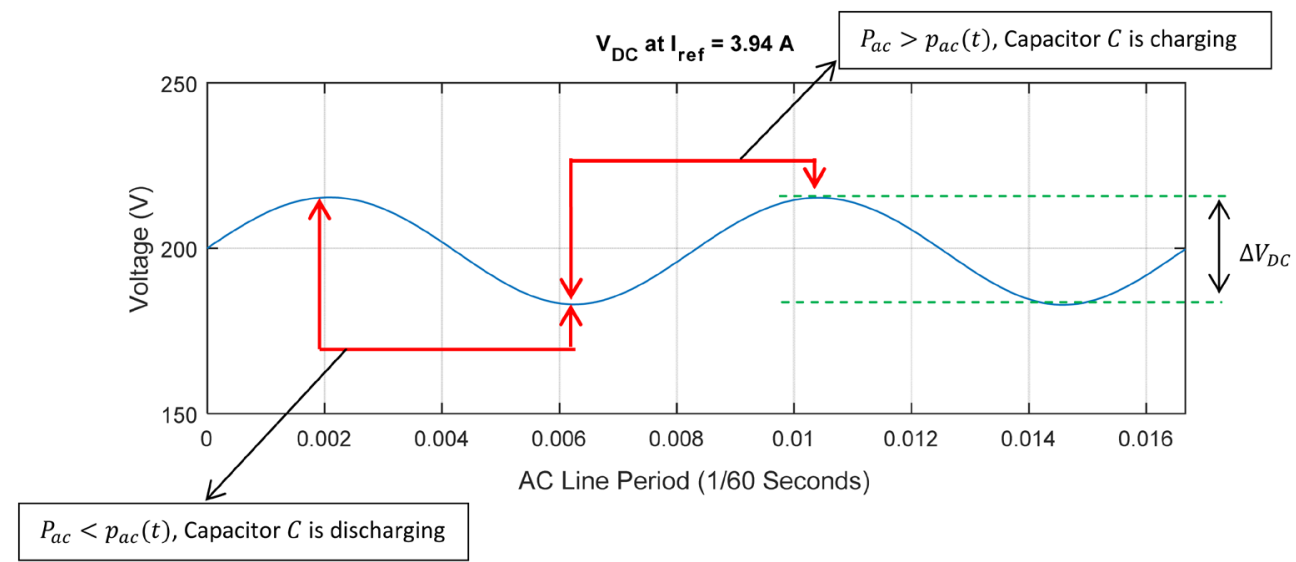

Figure 29. Analysis of the energy storage capacitor C.

Magnitude of the resulting ripple voltage $\Delta V_{D C}$ at twice the AC line frequency $(2 \times 60 \mathrm{~Hz}=120 \mathrm{~Hz}) \mathrm{de}-$ pends on the average power $P_{a c}$ and capacitance $C$. The energy supplied to the capacitor during charging from $V_{D C \min }$ to $V_{D C \max }$, i.e. when $P_{a c}>p_{a c}(t)$, is given by

$$
\Delta E_{C}=\int_{-T_{a c} / 8}^{T_{a c} / 8} P_{a c} \cos 2 \omega \mathrm{d} t=\frac{P_{a c}}{2 \omega} \int_{-\pi / 2}^{\pi / 2} \cos \theta \mathrm{d} \theta=\frac{P_{a c}}{\omega} .
$$

This energy must match the change in energy stored on the capacitor;

$$
\Delta E_{C}=\frac{1}{2} C V_{D C \max }^{2}=\frac{1}{2} C V_{D C \min }^{2}=C\left(V_{D C \max }-V_{D C \min }\right) \frac{V_{D C \max }+V_{D C \min }}{2} \approx C V_{D C} \Delta V_{D C} .
$$

Solving for the ripple voltage we get

$$
C V_{D C} \Delta V_{D C}=\frac{P_{a c}}{\omega} .
$$

And therefore

$$
\Delta V_{D C}=\frac{P_{a c}}{C V_{D C} \omega} .
$$

\section{Conclusion}

In this article, DC-DC converters and DC-AC inverters for PV-based communal grids have been reviewed, modeled and simulated in MATLAB/Simulink. The main functions of the power electronics are to ensure max- 
imum extraction of generated power and to efficiently deliver this power to a given set of loads, with minimum possible conversion/inversion losses. DC-DC converters ensure the PV systems to operate at maximum power points under all conditions while the inverters invert generated DC power into AC for utility grid interfacing or for AC loads. Transformerless inverters are more efficient, smaller in size and weight, cheaper, and less complex than transformer-based inverters and are thus recommended to small PV-based communal grids. Avoiding transformers however results in a galvanic connection of the grid and PV array. A two-stage DC-AC inverter with point of common coupling (PCC) at the DC-AC input has been identified as the most cost-effective operational configuration for small communal grids as only one inverter is used for the entire system as opposed to an inverter for every module string. This results in higher efficiencies, low cost, and low harmonic distortions when compared to systems with PCC at AC terminal.

\section{Acknowledgements}

This research is funded by Leeds International Research Scholarship.

\section{References}

[1] Mahdavi, J., Emadi, A. and Toliyat, H.A. (1997) Application of State Space Averaging Method to Sliding Mode Control of PWM DC/DC Converters. IEEE Industry Applications Society October 1997.

[2] (2003) IEEE Standard for Interconnecting Distributed Resources with Electric Power Systems. IEEE Std1547-2003, $1-16$.

[3] Turitsyn, K., Sulc, P., Backhaus, S., et al. (2010) Local Control of Reactive Power by Distributed Photovoltaic Generators. First IEEE International Smart Grid Communications (Smart-GridComm) Conference, Gaithersburg, MD, 4-6 October 2010, 79-84.

[4] Paal, E. and Tatai, E. (2010) Grid Connected Inverters Influence on Power Quality of Smart Grid. 14th International Power Electronics and Motion Control Conference (EPE/PEMC), Ohrid, Macedonia, 6-8 September 2010, T6-35-T639.

[5] Ettehadi, M., Ghasemi, H. and Vaez-Zadeh, S. (2011) Reactive Power Ranking for dg Units in Distribution Networks. 10th Environment and Electrical Engineering (EEEIC) Conference, Rome Italy, 8-11 May 2011, 1-4.

[6] Calais, M. and Hinz, H. (2002) Inverters for Single-Phase Grid Connected Photovoltaic Systems: Overview. IEEE PESC02 Conference, Cairns, June 2002, 1995-2000.

[7] Calais, M. and Hinz, H. (2002) Inverters for Single-Phase Grid Connected Photovoltaic Systems: Overview and Prospects. Centre for Renewable Energy Systems and Sustainable Technologies Australia (CRESTA).

[8] Calais, M. and Hinz, H. (1998) A Ripple Based Maximum Power Point Tracking Algorithm for Single Phase, Grid Connected Photovoltaic System. Solar Energy, 63, 277-282. http://dx.doi.org/10.1016/S0038-092X(98)00084-X

[9] Schimpf, F. and Norum, L.E. (2008) Grid Connected Converters for Photovoltaic, State of the Art, Ideas for Improvement of Transformerless Inverter. NORPIE/2008, Nordic Work on Power and Industrial Electronics, 9-11 June 2008.

[10] Simeonov, G. (2010) Novel Resonant Boost Converter for Distributed MPPT Grid-Connected Photovoltaic Systems. Master's Thesis, University of Toronto, Toronto.

[11] Kjaer, S., Pedersen, J. and Blaabjerg, F. (2005) A Review of Single-Phase Grid-Connected Inverters for Photovoltaic Modules. IEEE Transactions on Industry Applications, 41, 1292-1306.

[12] Erickson, R. and Rogers, A. (2009) A Microinverter for Building-Integrated Photovoltaics. 24th Annual IEEE Applied Power Electronics Conference and Exposition (APEC), Washington DC, 15-19 February 2009, 11-917.

[13] Henze, N., Engler, A. and Sahan, B. (2007) Performance of a Novel Three-Phase Photovoltaic Inverter for Module Integration. 22nd Photovoltaic Solar Conference and Exhibition, Milan, Italy, 2007, 3064-3069.

[14] Pires, V.F., Fernando, J. and Silva, A. (2002) Teaching Nonlinear Modelling, Simulation, and Control of Electronic Power Converters Using MATLAB/SIMULINK. IEEE Transactions on Education, 45, 253-261.

[15] Su, J., Chen, J. and Wu, D. (2002) Learning Feedback Controller Design of Switching Converters Via MATLAB/SIMULINK. IEEE Transactions on Education, 45, 307-315.

[16] Logue, D. and Krein, P. (2000) Simulation of Electric Machinery and Power Electronics Interfacing Using MATLAB/SIMULINK. 7th Workshop Computer in Power Electronics, Blacksburg, VA, 16-18 July 2000, 34-39. 